\title{
Um Centenário em Evidência: Alan Turing (1912-1954)
}

\section{A Centenary in Evidence: Alan Turing (1912-1954)}

\author{
Edilson Roberto Pacheco \\ Departamento de Matemática \\ Universidade Estadual do Centro-Oeste - UNICENTRO, Guarapuava, PR \\ Sandra Mara Guse Scós Venske \\ Departamento de Ciência da Computação \\ Universidade Estadual do Centro-Oeste - UNICENTRO, Guarapuava, PR \\ ssvenske@unicentro.br
}

Resumo: A relevância do tema no entorno do centenário de nascimento de Alan Turing é o foco do presente texto, que tem a finalidade de evidenciar aspectos biográficos e a expressão científica desse importante matemático. Sua produção estabeleceu as bases para o delineamento da então iminente Ciência da Computação e se projetou em outras áreas do conhecimento a partir de meados do século XX.

Palavras-chave: Alan Turing; história da ciência da computação; história da matemática.

\begin{abstract}
The relevance of the subject around the birth centenary of Alan Turing is the focus of this text, which aims to highlight biographical aspects and scientific expression of this important mathematician. His production established the foundation for the design at that time of the imminent Computer Science and has been projected from mid-twentieth century to other areas of knowledge.
\end{abstract}

Key words: Alan Turing; history of Computer Science; history of Mathematics.

Recebido em 02-10-2012 - Aceito em 29-01-2013.

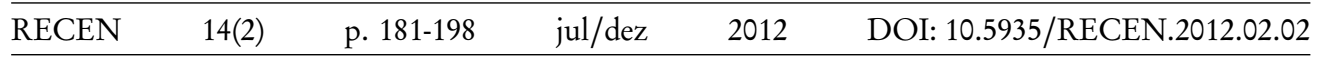




\section{Introdução}

No ano 2012, em muitos ambientes acadêmicos ao redor do mundo, eventos científicos comemorativos visam celebrar o nome de Alan Turing (1912-1954), matemático britânico, lógico e criptoanalista, cujos estudos foram basilares ao desenvolvimento do que veio a se configurar como Ciência da Computação. Sob a denominação "2012 Alan Turing Year"[1], vários eventos internacionais consonantes ${ }^{1}$ selam a relevância desse matemático na história da Matemática e da Ciência da Computação. No Brasil, também ocorreram eventos comemorativos a Turing. O presente texto é uma adaptação do conteúdo das duas palestras proferidas pelos autores no "Colóquio Alan Turing: 100 anos", realizado na véspera da data comemorativa do centenário.

Resolver um problema é uma representação razoável daquilo que os computadores fazem. Considerado o pai da Computação, Alan Turing publicou diversos trabalhos que ajudaram a tornar o que a Ciência da Computação é hoje. A máquina de Turing, por exemplo, formou a estrutura básica que fundamenta a Ciência da Computação moderna e a Teoria da Computabilidade.

No dia 23 de junho de 2012, Turing faria 100 anos e, se vivo estivesse, testemunharia a resultante de seus estudos, o impacto no desenvolvimento da Ciência da Computação e a projetação em áreas distintas do conhecimento, o que ratifica o foco de atenção que neste texto se direciona.

\section{Um breviário biográfico}

Dentre as modalidades de estudos em história da Matemática estão os que tratam de documentos históricos, obras, métodos e biografias [2]. A biografia (do grego antigo, bíos, vida e gráphein, escrever) é um gênero literário em que o autor narra a

\footnotetext{
1 "Turing Centenary Conference", Cambridge, june, 2012; "Turing Centennial Celebration", Princeton, may, 2012; "Alan Mathison Turing: Eroe Dell'Intelligenza Automatica", Roma, marzo, 2012; "Ano Alan Turing em Israel", Tel Aviv, abril, 2012; "Alan Turing Jaar 2012", juni, Nederland; "Alan Turing Jahr 2012", Deutschland; "Turing Centenary Events at Iceland", Reykjavic; "Alan Turing's Heritage", Lyon, France, july 2012; "The 7th International Computer Science Symposium in Russia"; "The Alan Turing Centenary Conference", Manchester, UK, june 22-26. Uma lista completa dos eventos pode ser encontrada em www.mathcomp.leeds.ac.uk/turing2012.
} 
história da vida de uma pessoa ou de várias pessoas. De um modo geral, atualmente, não exclusivo, as biografias relatam a vida de alguém depois de sua morte. Uma biografia é [3] uma "narração oral, escrita ou visual dos fatos particulares das várias fases da vida de uma pessoa ou personagem, ou seja, a história da vida de alguém".

Em face do escopo deste texto, não é pretensão engendrar aqui uma disposição biográfica sobre Alan Turing (Figura 1), haja vista a estabelecida limitação de páginas e, mesmo porque, isso já foi bem elaborado na, até agora, mais completa biografia produzida [4]. Todavia, a fim de ilustrar a apologia que ora se intenta, alguns elementos biográficos foram elencados a partir de fontes como a capital obra biográfica citada, o não menos notável livro de Leavitt [5], entre outras [6-8].

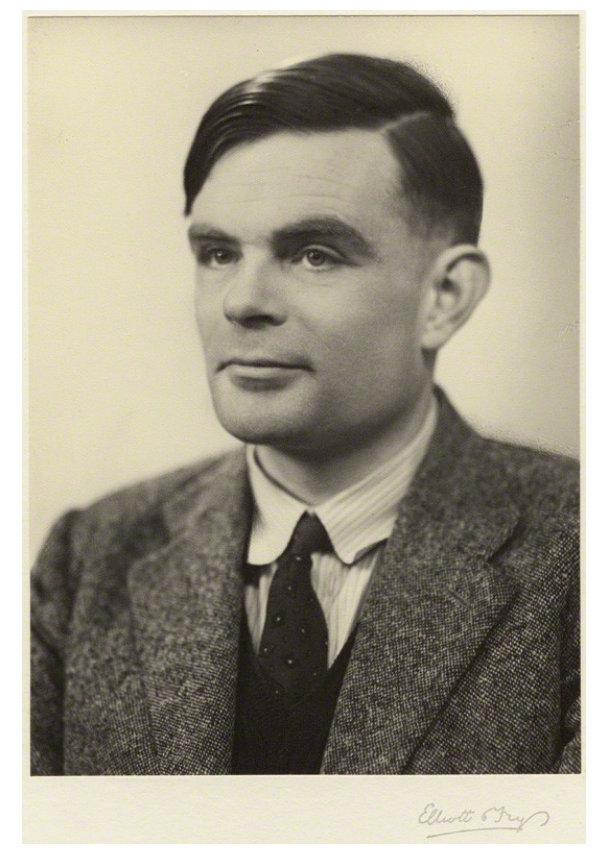

Figura 1. Alan Mathison Turing por Elliott E Fry, em 29.03.51 $(16,1 \mathrm{~cm} \times 11,7 \mathrm{~cm})$ Foto fornecida por sua mãe, Ethel Sara Turing. National Portrait Gallery, London [9]

O quase esquecimento do nome de Alan Turing, após sua morte, foi solapado pelo efeito da pioneira e insigne biografia produzida por Andrew Hodges, Alan Turing: the enigma, (1983). Somente há poucas décadas, o nome de Turing passou, de sucintas notas em fontes de história da Matemática $[10,11]$, a mais centralidade 
em obras e textos posteriores $[12,13]$ e na edição mais recente do conhecido livro de Boyer [14].

Conforme essas fontes, Alan Mathison Turing nasceu em 23 de junho de 1912, em Paddington, Londres. Julius Mathison, seu pai era membro do serviço civil inglês na Índia e sua mãe, Ethel Sara Stoney Turing, era filha do engenheiro chefe da linha de trens de Madras, Índia. Quando Alan estava com apenas um ano de idade e seu irmão John com cinco anos, sua mãe foi acompanhar o pai na Índia, deixando os filhos na Inglaterra aos cuidados de um casal conhecido. Seus primeiros anos se passaram com a família Ward, numa localidade próxima e seus pais os visitavam casualmente. Nesse período, Alan passou a desenvolver uma gagueira, fato que, em algumas biografias, é atribuído como consequência da ausência dos pais. Como era filho de classe média, teve uma educação que correspondia à da pequena aristocracia inglesa. Precocemente, suas capacidades intelectuais afloraram; demonstrava interesse por números antes de aprender a ler. Com dez anos de idade, foi enviado à Hazelhurst Preparatory School, onde, segundo relatos dos professores e também de sua mãe, foi considerado "um aluno médio"e que procurava uma independência em suas próprias ideias.

Em 1926, passou a cursar o Ensino Médio na Sherborne School, em Dorset, onde descobriu seu interesse para Matemática e estabeleceu uma estreita amizade com Christopher Morcom, aluno que era conhecido como destaque em Matemática. Turing se apaixonou pelo amigo, uma experiência casta e perturbante para ele, num país e numa época em que homossexualidade era passível de punição com prisão. Logo a ambivalência se instaurou, da felicidade de se ter um amigo e um amor platônico à repentina e traumática morte de Morcom em 1930, vítima de tuberculose bovina contraída por leite contaminado.

Após retomar força e motivação, em 1931, Turing ingressa no King’s College da Universidade de Cambridge, para estudar matemática. Lê textos de Russell² e von Neumann ${ }^{3}$ sobre mecânica quântica, probabilidade e lógica. Em 1933, ocorre a

\footnotetext{
${ }^{2}$ Bertrand Russell (1872-1970), influente matemático, filósofo e lógico britânico. Recebeu o prêmio Nobel de Literatura de 1950.

3 John von Neumann (ou Margittai Neumann János Lajos, 1903-1957), húngaro naturalizado estadunidense. Devido à sua contribuição em muitas áreas distintas da Matemática, é considerado um dos
} 
ascensão de Hitler na Alemanha e eclode o movimento anti-guerra na Grã-Bretanha, do qual Turing toma parte.

Em 1934, gradua-se com distinção e, no ano seguinte, aos 22 anos, submete a dissertação On the Gaussian Error Function e se torna pesquisador do King's College. Nesse mesmo ano, frequenta o Curso Avançado de Fundamentos da Matemática, ministrado pelo matemático Max Newman, que trata, entre outros temas, da "incompletude de Gödel"e da "decidibilidade de Hilbert", questões que instigaram Turing.

Em 1936, submete o artigo On Computable Numbers, with an Application to the Entscheidungsproblem, publicado no início de 1937, no Proceedings of the London Mathematical Society. Nesse artigo [15], as ideias de computabilidade, de uma máquina para computar, são esboçadas a partir da questão central: "Quais são os possíveis processos que podem ser utilizados na computação de um número?"Define que "The 'computable' numbers may be describe briefly as the real numbers whose expressions as a decimal are calculable by finite means. "(...) "According to my definition, a number is computable if its decimal can be written down by a machine. "([15]p.230) $\mathrm{O}$ artigo contém três partes: i) A ideia do computable number e da máquina de computação; ii) o conceito de uma máquina universal; e iii) a prova da insolubilidade do Entscheidungsproblem ${ }^{4}$. Essas ideias encontram-se mais detalhadas na sequência deste texto, em tópico específico.

No mesmo ano, Turing envia o rascunho desse artigo a Newman, que havia recebido pelo correio uma separata de um artigo escrito pelo matemático estadunidense Alonzo Church, de Princeton, que havia trabalhado no Entscheidungsproblem e proposto uma formalização da noção de "efetivamente computável", por meio do conceito de lâmbda-definibilidade. Dada a semelhança entre os temas, Newman escreve a Church apresentando Turing e, dessa interlocução, Turing se torna estudante de pós-graduação no Instituto de Estudos Avançados da Universidade de Princeton,

mais importantes matemáticos do século XX.

${ }^{4}$ Termo alemão para problema de decisão. É um problema da lógica, proposto em 1928 pelo matemático alemão David Hilbert (1862-1943), que consiste em encontrar um algoritmo genérico para determinar se um dado enunciado pode ser provado. Em 1936, de forma independentemente, Church e Turing mostraram que é impossível decidir algoritmicamente se um enunciado na aritmética é verdadeiro ou falso. 
que era o centro mais prestigioso de lógica, e onde conheceu o matemático John von Neumann.

No período 1936-38, Turing trabalha com Church em um artigo para estabelecer a equivalência da compatibilidade entre computabilidade e definibilidadelâmbda. Também escreve ensaios e ministra palestra sobre seus estudos. Em 1938, conclui seu $\mathrm{PhD}$ em Lógica Matemática e retorna à Inglaterra, ao King’s College.

Em Cambridge, passa a frequentar o curso ministrado por Wittgenstein ${ }^{5}$ sobre Filosofia da Matemática. Também, retoma seus estudos sobre um dispositivo para investigar a Hipótese de Riemann ${ }^{6}$. Entretanto, em 1939, eclode a Segunda Guerra Mundial e, um dia após a Inglaterra declarar guerra à Alemanha, Turing passa a trabalhar para a inteligência britânica num centro especializado em quebra de códigos - o Government Code and Cypher School, Bletchley Park, Buckinghamshire. Por um tempo, foi chefe da Hut 8 , seção responsável pela criptoanálise da frota naval alemã. Em maio de 1940, Turing e o matemático Welchmann ${ }^{7}$ desenvolvem e colocam em funcionamento a Bombe - máquina construída com base no projeto do criptologista polonês Marian Rejewski para decriptar as mensagens cifradas pelos alemães ${ }^{8}$ nas máquinas Enigma da Luftwaffe.

De novembro de 1942 a março de 1943, Turing trabalha com decifradores no departamento de criptoanálise da Marinha dos Estados Unidos para desenvolver a decodificação e um sistema de codificação de mensagens de voz. Volta a Cambridge e retorna a Bletchley Park para trabalhar, sob direção de Max Newman, na quebra do código Fish, que era gerado pela máquina alemã Lorenz. O projeto da máquina Colossos havia iniciado e Turing foi fundamental no desenvolvimento dessa eficiente máquina.

\footnotetext{
${ }^{5}$ Ludwig Joseph Johann Wittgenstein (1889-1951), filósofo austríaco naturalizado britânico, contribuiu significativamente na lógica, filosofia da linguagem e filosofia da matemática. É um dos filósofos mais importantes do século XX.

${ }^{6}$ Hipótese matemática, publicada em 1859 pelo matemático alemão Georg Friedrich Bernhard Riemann (1826-1866). A conjectura afirma que os zeros não-triviais da função zeta de Riemann pertencem todos a uma "linha crítica". O objetivo de Turing era encontrar soluções fora dessa linha.

${ }^{7}$ William Gordon Welchman (1906-1985), matemático britânico-estadunidense.

${ }^{8}$ No início de 1942, os criptoanalistas de Bletchley Park decodificavam cerca de 39.000 mensagens interceptadas a cada mês, quantia que, posteriormente, aumentou para mais de 84.000 por mês. (britannica.com/EBchecked/topic/609739/Alan-M-Turing).
} 
No final da guerra, em 1945, Turing estava trabalhando em Hanslope Park, com criptografia de voz, num projeto denominado Dellilah. É então convidado pelo National Physical Laboratory (NPL), em Teddington, e passa a liderar um projeto para a construção de uma máquina automática de computação - o ACE (Automatic Computing Engine). Nesse mesmo ano, é premiado com a Ordem do Império Britânico, por sua contribuição vital durante a guerra. Decepcionado, entretanto, com a política de verbas para empreendimentos científicos, deixou o NPL antes da finalização do ACE.

Desde o período como estudante universitário, Turing praticava corridas, realizando, eventualmente, o caminho de Bletchley Park a Londres (aproximadamente $60 \mathrm{~km}$ ) correndo. Em 1945, participou como membro do Walton Athletic Club e venceu campeonatos de 3 e 10 milhas em tempo recorde. Em 1947, alcançou o

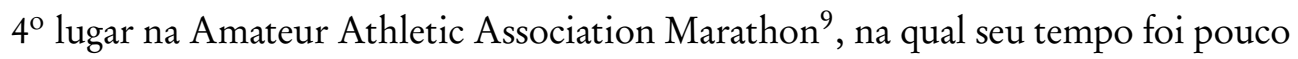
menor que o do vencedor em 1948 dos jogos olímpicos de Londres.

Após seu retorno a Cambridge, em 1947, onde fica cerca de um ano, passa a se interessar por neurologia e psicologia. Nesse período, também, deixa extravasar alguns comportamentos homossexuais. Depois de um ano, assume o cargo de vicediretor do laboratório de computação da Universidade de Manchester, onde estava sendo construído o MADAM (Manchester Automatic Digital Machine), primeiro computador eletrônico com programa armazenado.

Decorrente de suas incursões filosóficas e de seu profundo conhecimento de lógica Turing publica, em 1950, Computing machinery and intelligence, [16] no qual, a partir da questão "I propose to consider the question, Can machines think?" estabelece o objetivo de determinar se máquinas podem exibir comportamento inteligente. Esse procedimento, que passou a ser conhecido como teste de Turing, encontra-se mais detalhado em tópico específico deste texto.

No ano seguinte, com apenas 39 anos de idade, é eleito membro da Royal Society, de Londres, pelo seu trabalho sobre máquinas de Turing, em 1937. Passa a se interessar pelo estudo do desenvolvimento de padrões em organismos e tenta desenvolver uma teoria matemática do crescimento orgânico. Em seu artigo The

\footnotetext{
9 Jornal britânico The Times, 25.8.1947.
} 
Chemical Basis of Morphogenesis, publicado em 1952, parte das questões: "Como as coisas crescem?"e "Como a matéria ganha forma?"e prescreve que: (...) The purpose of this paper is to discuss a possible mechanism by which the genes of a zygote may determine the anatomical structure of the resulting organism. Sinaliza que (...) The full understanding of the paper requires a good knowledge of mathematics, some biology, and some elementary chemistry.

Nesse tempo, como homossexual, foi proibido de falar no assunto devido à imperante Lei de Segredos Oficiais e passou a ser foco de atenção de investigadores, já que havia trabalhado em um serviço secreto governamental. Um episódio, contudo, fomentou negativamente essa situação e se tornou catastrófico na vida de Turing. A relação casual que mantinha com um rapaz de Manchester tornou-se pública e conturbada, após Turing procurar a polícia para registrar o fato de ter sido roubado; todavia, o que se sucedeu foi inusitado. Veio à tona a sua condição homossexual e, ao invés de o suposto ladrão ser detido, Turing foi acusado de indecência flagrante. Algumas semanas depois, foi julgado por vícios impróprios ${ }^{10}$, por força da Lei dos Crimes Sexuais. A sentença a ele imputada foi dois anos de encarceramento ou um ano de tratamento de redução da libido, à base de hormônios. Confessou-se culpado para, livre, poder continuar trabalhando. Sofreu humilhações em público e foi impedido de acompanhar estudos sobre computadores. A terapia à base de estrogênio provocou nele castração química, deixando-o impotente e com o efeito colateral de causar o crescimento de seios. Como consequência, sucumbiu melancolicamente, apresentou sentimentos de aflição.

Em 8 de junho de 1954, em Wilmslow, Cheshire, proximidades de Manchester, Turing é encontrado, pela governanta, morto em casa. Ao lado de sua cama havia uma maçã meio comida. Na necrópisa, a causa da morte foi envenenamento por

\footnotetext{
${ }^{10}$ Em 1885, o Parlamento britânico aprovou a Emenda Labouchere, que coibia todos os atos homossexuais entre homens ("atos de grande indecência") considerando-os atentado violento ao pudor, tornando-os crime. Após a condenação de homens famosos por crimes homossexuais, o Relatório do Comitê Departamental de Crimes Homossexuais e Prostituição, de 4 de setembro de 1957, recomendou que "comportamento homossexual voluntário privado entre adultos não deveria mais constituir crime". Ainda, "A função do direito não é, a nosso ver, intervir na vida privada de cidadãos, ou buscar coagir qualquer tipo de comportamento específico". Isso implicou sanção, em 1967, da Lei dos Crimes Sexuais, na Inglaterra e no País de Gales, a qual revogava a Lei dos Crimes contra a Pessoa (1861) e a Emenda Labouchere (1885). Estendeu-se à Escócia, em 1980, e à Irlanda do Norte em 1982.
} 
cianeto de potássio e, segundo o inquérito divulgado dois dias depois, ele tinha cometido suicídio. Em 12 de junho, Turing foi cremado em Woking, Surrey.

Frisando o que assinala Turing (p.4, 1937)[5]:

Agora Turing é tido como um dos mais importantes cientistas do século XX. Mesmo assim, os mais populares relatos sobre seu trabalho ou falham em mencionar claramente sua homossexualidade, ou a apresentam como uma mancha repulsiva, e no final trágico, de uma carreira de outra forma considerada estelar.

\section{A Máquina de Turing e o Teste de Turing}

Em 1936, Alan Turing propôs um modelo poderoso, denominado por ele como Máquina Universal, no artigo intitulado On computable numbers, with an application to the Entscheidungsproblem [15]. Nesse trabalho, Turing apresenta uma máquina abstrata de memória ilimitada e irrestrita - hoje conhecida como Máquina de Turing (MT), a fim de formalizar a noção de procedimento mecânico (algoritmo) que ele chamou de computabilidade efetiva. Apesar da máquina de Turing não ter sido implementada fisicamente pelo seu autor, o processo computacional foi matematicamente demonstrado e provado no artigo.

Ele descreveu em termos matematicamente precisos como pode ser poderoso um sistema formal automático, com regras muito simples de operação [17].

Uma MT é um modelo preciso de um computador de propósito geral. Uma MT pode realizar tudo o que um computador atual real pode fazer. A MT é um dispositivo teórico que se restringe a operações abstratas ao considerar apenas memória, estados e transições e não questões relacionadas à implementação.

O modelo da MT utiliza uma fita infinita como sua memória ilimitada. A máquina tem uma cabeça que pode ler e escrever símbolos e mover sobre a fita. Inicialmente, a fita contém somente a cadeia de entrada e está em branco em todo o restante. Se a máquina precisa armazenar informação, ela pode escrever essa informação sobre a fita. Para ler a informação que escreveu, a máquina pode mover sua cabeça de volta sobre a posição onde a informação foi escrita. A máquina continua a computar até que decide produzir uma saída [18].

A figura 2 mostra a visualização do modelo de uma máquina de Turing [18]. A máquina possui um controle finito, que pode se encontrar em qualquer estado de 
um conjunto finito de estados, e também possui uma fita dividida em células, que pode conter qualquer símbolo de um número finito de símbolos.

Em uma MT, inicialmente, é colocada na fita uma entrada, que é uma cadeia de comprimento finito de símbolos do alfabeto de entrada. A cabeça da fita fica sempre posicionada em uma das células da fita e, inicialmente, a cabeça encontrase na célula mais a esquerda da cadeia de entrada. Um movimento da máquina é uma função do estado do controle finito e do símbolo de fita varrido. Em um movimento, a máquina pode assumir três ações possíveis: i) mudar de estado; ii) escrever um símbolo de fita na célula varrida; iii) movimentar a cabeça da fita para a esquerda ou para a direita.

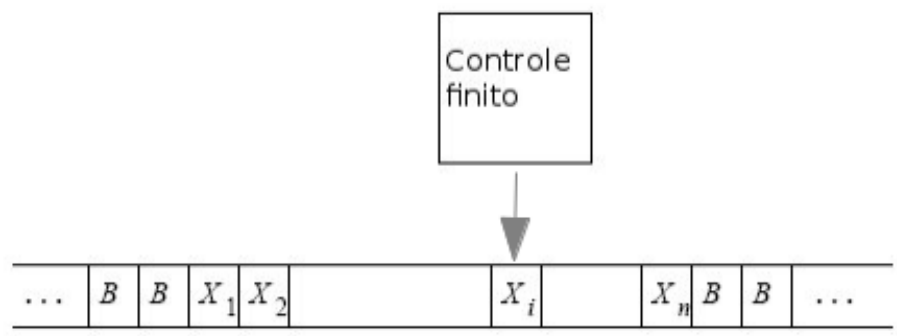

Figura 2. Uma máquina de Turing [18].

Formalmente, uma MT é:

$$
\mathrm{M}=\left(\mathrm{Q}, \Sigma, \Gamma, \delta, q_{0}, \mathrm{~B}, \mathrm{~F}\right)
$$

sendo:

- Q: conjunto finito de estados do controle finito;

- $\sum$ : conjunto finito de símbolos de entrada;

- $\Gamma$ : conjunto completo de símbolos de fita $\left(\sum\right.$ é subconjunto de $\left.\Gamma\right)$

- $\delta$ : função de transição. Os argumentos de $\delta(\mathrm{q}, \mathrm{X})$ são um estado q e um símbolo da fita X. O valor de $\delta$ (q, X) é (p, Y, D) em que:

- p é o próximo estado em Q; 
- Y é o símbolo em $\Gamma$, gravado na célula que está sendo varrida, que substitui o símbolo que estava na célula;

- D é uma direção (ou sentido) - L ou R, esquerda (left) ou direita (right), respectivamente, informando o sentido em que a cabeça se move.

- $q_{0}$ : estado inicial (elemento de Q);

- B: símbolo branco (está em $\Gamma$, mas não está em $\Sigma$ );

- F: conjunto de estados finais ou de aceitação (subconjunto de Q).

A seguinte MT aceita a linguagem $\left\{0^{n} 1^{n} \mid \mathrm{n} \geq 1\right\}$. A sua especificação formal é: $\mathrm{M}=\left(\left\{q_{0}, q_{1}, q_{2}, q_{3}, q_{4}\right\},\{0,1\},\{0,1, \mathrm{X}, \mathrm{Y}, \mathrm{B}\}, \delta, q_{0}, \mathrm{~B},\left\{q_{4}\right\}\right)$, sendo $\delta$ dada pela tabela 1. À medida que $\mathrm{M}$ executar sua computação, haverá alguns 0 's trocados por X's, seguidos por alguns O's que ainda não foram trocados por X. Em seguida, haverá alguns 1's que foram trocados por Y's e 1's que ainda não foram trocados por Y's.

Tabela 1. MT para aceitar $\left\{0^{n} 1^{n} \mid n \geq 1\right\}$.

\begin{tabular}{cccccc}
\hline & 0 & $\mathbf{1}$ & $\mathbf{X}$ & $\mathrm{Y}$ & $\mathbf{B}$ \\
\hline$q_{0}$ & $\left(q_{1}, \mathrm{X}, \mathrm{R}\right)$ & & & $\left(q_{3}, \mathrm{Y}, \mathrm{R}\right)$ & \\
$q_{1}$ & $\left(q_{1}, \mathrm{O}, \mathrm{R}\right)$ & $\left(q_{2}, \mathrm{Y}, \mathrm{L}\right)$ & & $\left(q_{1}, \mathrm{Y}, \mathrm{R}\right)$ & \\
$q_{2}$ & $\left(q_{2}, \mathrm{O}, \mathrm{L}\right)$ & & $\left(q_{0}, \mathrm{X}, \mathrm{R}\right)$ & $\left(q_{2}, \mathrm{Y}, \mathrm{L}\right)$ & \\
$q_{3}$ & & & & $\left(q_{3}, \mathrm{Y}, \mathrm{R}\right)$ & $\left(q_{4}, \mathrm{~B}, \mathrm{R}\right)$ \\
$q_{4}$ & & & & & \\
\hline
\end{tabular}

Como exemplo de computação de aceitação por M, tem-se a entrada 0011. Inicialmente, $\mathrm{M}$ está no estado $q_{0}$, varrendo o primeiro 0 . A função de transição para $q_{0}$ lendo $\mathrm{O}$ é $\left(q_{1}, \mathrm{X}, \mathrm{R}\right)$, ou seja, escrever o $\mathrm{X}$ na fita, movimentar-se para a direita na fita e mudar para o estado $q_{1}$. A máquina segue as transições sucessivamente até encontrar-se no estado $q_{4}$, que é o estado final da máquina, no qual ela para de computar.

Atualmente, considera-se mais conveniente pensar em MTs como reconhecedores de linguagens ou, de modo equivalente, solucionadores de problemas. Contudo, a visão original de Turing sobre sua máquina era a de um computador de funções. 
Seguindo esse raciocínio, os inteiros eram representados em unário, como blocos de um único caractere e a máquina fazia os cálculos alterando os comprimentos dos blocos ou construindo novos blocos em outro lugar na fita.

Turing demonstrou também que seu dispositivo permitiria resolver muitos problemas, mas que também havia alguns que não seriam possíveis, porque não haveria jeito de se prever se o dispositivo pararia ou não [17]. Turing provou então formalmente o teorema relacionado a esse raciocínio:

Teorema da Parada: Dado um programa P qualquer para uma Máquina de Turing e uma entrada $\mathrm{E}$ qualquer de dados para esse programa, não existe uma Máquina de Turing específica que pare após um número finito de passos, e que diga se $\mathrm{P}$ em algum momento encerra sua execução ao processar E.

Em outubro de 1950, Turing também propôs, em um artigo intitulado Computing Machinery and Intelligence [16] um teste denominado Jogo da Imitação (conhecido atualmente como Teste de Turing), para determinar se máquinas podem exibir comportamento inteligente. Turing inicia o artigo com a pergunta "Can machines think?" (Podem as máquinas pensar?).

No exemplo original do artigo de Turing, um interrogador humano conversa em linguagem natural (utilizando um canal unicamente de texto) com outro humano e uma máquina. Essa máquina foi criada para ter desempenho de ser humano, a fim de que o interrogador fique sem saber se está conversando com a máquina ou com o outro ser humano. Se o interrogador não puder diferenciar com segurança a máquina do humano, então é dito que a máquina passou no teste.

A Máquina Universal - num texto repleto de formalismos matemáticos, e o Jogo da Imitação - um trabalho mais intuitivo até filosófico, são muito interessantes, especialmente considerando que foram escritos há mais de 60 anos. Turing insiste em seguir o modelo humano, tanto quanto possível [19], tanto na proposta de passo-a-passo de funcionamento da máquina Universal quanto no Jogo da Imitação. Em ambos os trabalhos, ele não coloca questões sobre como projetar as máquinas, mas, ele descreve em detalhes substanciais a forma com que o aprendizado das máquinas deve ocorrer. Esses detalhes pensados por Turing representam até a atualidade a forma com que os computadores trabalham. Uma MT pode simular o espaço 
de armazenamento e o controle de um computador real, usando uma única fita para armazenar todos os locais e seu conteúdo (registradores, memória principal, discos e outros dispositivos de armazenamento). Assim, é possível saber que algo que não possa ser feito por uma MT não poderá ser realizado por um computador real.

Conforme Fonseca Filho (2007)[17], o próprio Turing escreveu:

Computar é normalmente escrever símbolos em um papel. Suponha que o papel é quadriculado, podendo ser ignorada a bidimensionalidade, que não é essencial. Suponha que o número de símbolos é finito. [...]. O comportamento do(a) computador(a) é determinado pelos símbolos que ele(a) observa num dado momento, e seu estado mental nesse momento. Suponha que exista um número máximo de símbolos ou quadrículas que ele(a) possa observar a cada momento. Para observar mais serão necessárias operações sucessivas. Admitamos um número finito de estados mentais [...]. Vamos imaginar que as ações feitas pelo(a) computador(a) serão divididas em operações tão elementares que são indivisíveis. Cada ação consiste na mudança do sistema computador(a) e papel. O estado do sistema é dado pelos símbolos no papel, os símbolos observados pelo(a) computador(a) e seu estado mental. A cada operação, não mais de um símbolo é alterado, e apenas os observados são alterados. Além de mudar símbolos, as operações devem mudar o foco da observação, e é razoável que esta mudança deva ser feita para símbolos localizados a uma distância fixa dos anteriores. [...] Algumas destas operações implicam mudanças de estado mental do computador(a) e portanto determinam qual será a próxima ação.

Em suma, Alan Turing acabou por ajudar a definir, antes mesmo de existir o computador propriamente, a natureza da computação, e as implicações e limites do pensamento humano por meio de uma máquina.

\section{Alguns reconhecimentos e tributos ulteriores}

- A. M. Turing Prize - Prêmio instituído em 1966 pela ACM - Association for Computing Machinery" 11 [20] - para "an individual selected for contributions of a technical nature made to the computing community". Estipulou-se que "The contributions should be of lasting and major technical importance to the computer field". O prêmio A. M. Turing é reconhecido como a mais alta distinção na Ciência da Computação, como se fosse o prêmio Nobel da Computação. Desde 2007, o prêmio é acompanhado da quantia de 250 mil dólares america-

\footnotetext{
${ }^{11}$ Fundada em 1947, tem sede em Nova York. É a maior e mais prestigiosa sociedade científica computacional mundial. Atualmente, conta com mais de cem mil membros. (acm.org)
} 
nos, patrocinada por Intel Corporation e Google.

- Em 1996, inspirado na biografia de Turing, por Hodges, foi lançado, em nível mundial, o filme Breaking the Code, uma biografia e documentário de $75 \mathrm{~min}$, produzido pela BBC para a televisão, sob direção de Herbert Wise, roteiro de Hugh Whitemore e Derek Jacobi no papel de Turing.

- Em 23 de junho de 1998, data que seria o 86ª aniversário de Turing, seu biógrafo A. Hodges desvelou, em Warrington Crescent, London, a placa azul inglesa oficial na casa onde Turing nasceu e passou parte de sua infância. A placa contém a inscrição: "ALAN TURING 1912-1954 Code-breaker and $\mathrm{Pi}$ onner of Computer Science was born bere".

- 1999 - Em uma pesquisa publicada pela revista Time ${ }^{12}$, [21], o nome de Alan Turing figurou na lista dos 20 maiores cientistas e pensadores da história.

- 2001 - Uma escultura de Turing, em bronze, foi colocada em Sackville Park, na área central de Manchester, na data de seu aniversário, 23 de junho.

- Em 21 de agosto de 2002, sob o título 100 Great British Heroes, a rede britânica $\mathrm{BBC}$ divulgou o resultado da votação realizada para determinar quem o Reino Unido considerava os 100 Greatest Britons de todos os tempos. O nome de Alan Turing é o $21^{\circ}$ da lista dos 100 "maiores"britânicos.

- Em junho de 2004 , no $50^{\circ}$ aniversário da morte de Turing, foi afixada na casa onde ele morreu, a placa: ALAN TURING 1912-1954 founder of computer science and cryptographer whose working was key to breaking the wartime Enigma codes, lived and died here.

- 2004 - Universidade de Surrey, Inglaterra - foi instalada uma grande escultura de bronze em um local destacado no campus.

- 2007, junho - Uma escultura foi colocada no Bletchley Park Museum.

\footnotetext{
${ }^{12}$ Time, março 1999, v.153, n. 12. (time.com/time/magazine/0,9263,7601990329,00.html).
} 
- Em 2007, o Departamento de Matemática da Universidade de Manchester foi movido para novo prédio, nominado Alan Turing Building. A sala de computação do King's College, em Cambridge, passou a ser designada Turing Computer Room, homenagem ao estudante de 1931 e bolsista em 1935.

- Após uma campanha via internet, o primeiro-ministro do Reino Unido, Gordon Brown, em 10 de setembro de 2009, apresentou desculpas formais em nome do governo britânico pelo tratamento preconceituoso dado a Alan Turing, que ocasionou seu suicídio 55 anos antes. O jornal britânico The Telegraph [22] registrou esse pronunciamento ${ }^{13}$, cuja matéria destaca, em subtítulo, I'm prond to say sorry to a real war hero.

- Um busto de Turing foi colocado na parede do prédio da Ciência da Computação, na Universidade de Oregon, EUA.

- Em 23 de junho de 2012, o buscador Google apresentou [23] um Doodle interativo $^{14}$ no qual os visitantes podiam mudar as instruções de uma máquina de Turing.

\section{Considerações finais}

A percepção genial de Turing foi a substituição da noção intuitiva de procedimento efetivo por uma ideia formal, matemática. O resultado foi a construção de uma conceituação matemática da noção de algoritmo, uma noção que ele modelou, baseando-se nos passos que um ser humano dá quando executa um determinado cálculo ou cômputo. Ele formalizou definitivamente o conceito de algoritmo.

Seu desempenho é considerado capital na vitória aliada na Segunda Guerra Mundial. No âmbito pessoal, foi vítima da intolerância e da perseguição, a despeito de

\footnotetext{
${ }^{13}$ No pronunciamento de Gordon, "Turing was a quite brilliant mathematician, most famous for his work on breaking the German Enigma codes. It is no exaggeration to say that, without his outstanding contribution, the history of the Second World War could have been very different". Destaca que "The debt of gratitude he is owed makes it all the more horrifying, therefore, that he was treated so inhumanely."e ainda: "I am pleased to have the chance to say how deeply sorry I and we all are for what happened to him."Finaliza com "This recognition of Alan's status as one of Britain's most famous victims of homophobia is another step towards equality, and long overdue."(telegraph.co.uk).

${ }^{14} \mathrm{O}$ doodle pode ser visto em: http://www.google.com/doodles/alan-turings-100th-birthday.
} 
sua brilhante definição matemática. Como efeito, foi conduzido ao ostracismo, mesmo com uma incomparável qualificação.

Conforme extratos biográficos, destaca-se a admiração fanática de Turing ao filme "Branca de Neve e os sete anões", de Walt Disney, que viu pela primeira vez em 1938 e reviu dezenas de vezes. Como características pessoais, são evidenciadas: modéstia, ingenuidade, distração, distanciamento da ambição mundana e alheamento. Ademais, que Turing, que trabalhou na Enigma, era, ele próprio, também um enigma.

Enfim, quanto às realiz(ações) do considerado "fundador da Ciência da Computação", elas, em uma paráfrase, expressam-se por si.

\section{Referências}

[1] 2012 The Alan Turing year. Disponível em http://www.mathcomp.leeds.ac.uk/turing2012/. Acesso em mai/2012

[2] BARONI, R. S.; NOBRE, S. A pesquisa em história da matemática e suas relações com a educação matemática. In: BICUDO, M. (Org.). Pesquisa em educação matemática: concepções e perspectivas. São Paulo: Ed. UNESP, (Seminários \& Debates), 1999.

[3] HOUAISS, A. Dicionário Houaiss da língua portuguesa. 1.ed. Rio de Janeiro: Objetiva, 2009.

[4] HODGES, A. Alan Turing: enigma. The centenary edition. Princeton: Princeton University Press, 2012.

[5] LEAVITT, D. O homem que sabia demais. Alan Turing e a invenção do computador. Trad. Samuel Dirceu. São Paulo: Novo Conceito, 2007.

[6] COPELAND, B. J. Alan M. Turing. Disponível em http://www.britannica.com/EBchecked/topic/609739/Alan-M-Turing. Acesso em ago/2012. 
[7] HODGES, A. Alan Turing. Disponível em: http://turing.org.uk. Acesso em $\mathrm{abr} / 2012$.

[8] The Turing digital archive. Disponível em http://www.turingarchive.org/. Acesso em mai/2012.

[9] Alan Mathison Turing Portrait. Disponível em http://www.npg.org.uk/collections/search/portrait/mw165875/AlanMathison-Turing?. Acesso em abr/2012.

[10] CHARP, S. O computador digital moderno. In: DAVIS, H. Computação. São Paulo: Atual, São Paulo: Atual,(Tópicos de História da Matemática para uso em sala de aula), v.2, p.79-83, 1992.

[11] STRUIK, D. J. História concisa das matemáticas. Trad. João Cosme S. Guerreiro. Lisboa: Gradiva, 1987.

[12] KATZ, V. J. A history of mathematics: an introduction. 2.ed. AddisonWesley, 1998.

[13] O’CONNOR, J. J.; ROBERTSON, E. F. Alan Mathison Turing. MacTutor history of mathematics, 2003. Disponível em http://www-history.mcs.standrews.ac.uk/Biographies/Turing.html. Acesso em fev/2012.

[14] BOYER, C. História da matemática. São Paulo, Blucher, 2012.

[15] TURING, A. M. On computable numbers, with an application to the Entscheidungsproblem. Proceedings of the London Mathematical Society, Series 2, v.42, p.230-265, 1937.

[16] TURING, A. M. Computing machinery and intelligence. Mind, v.59, p.433$460,1950$.

[17] FONSECA FILHO, C. História da computação [recurso eletrônico]: O caminho do pensamento e da tecnologia. Porto Alegre: EDIPUCRS, 2007. 
Revista Ciências Exatas e Naturais, Vol.14, n², Jul/Dez 2012

[18] HOPCROFT, J. E.; ULLMAN, J. D.; MONTWANI, R. Introdução à teoria de autômatos, linguagens e computação. 2.ed. Rio de Janeiro: Elsevier, 2002.

[19] TURING, A. M. Intelligent machinery, in D.M.B. Meltzer ed. Machine intelligence 5, Edinburgh University Press, p.3-23. Originally, a National Physics Laboratory Report, 1948.

[20] Association for Computing Machinery. Disponível em http://www.acm.org/. Acesso em ago/2012.

[21] Time 100: The century greatest minds. Disponível em http://www.time.com/time/magazine/0,9263,7601990329,00.html. Acesso em set/2012.

[22] The Telegraph. Disponível em http://www.telegraph.co.uk/. Acesso em set/2012.

[23] Google. Alan Turing's birthday. Disponível em http://www.google.com/doodles/alan-turings-100th-birthday. Acesso em jun/2012. 